Martin Kusch

\title{
Discursive formations and possible worlds A reconstruction of Foucault's archeology
}

In this paper I shall reconstruct some of the central concepts and ideas of Michel Foucault's The Archeology of Knowledge (=AK, 1969/1974). The notions in question are those of a "statement", a "discursive formation", a "rupture", and an "archeological description". These concepts seem to stand in need of further elaboration despite the many remarkable studies of Foucault's thought that have been published over the last decade. ${ }^{1}$ For instance, the single most important investigation into Foucault's methodology and development, Michel Foucault. Beyond Structuralism and Hermeneutics (1982), by Hubert L. Dreyfus and Paul Rabinow, quickly passes over the notion of the statement, does not investigate the relation between statements and discursive formations, and fails to give heed to the influence Foucault's conception of discursive formations exercizes on his archeological method and his concept of rupture.

\section{What is a Foucauldian statement?}

Archeology, Foucault tells us, is the study of statements (énoncés) and their interconnections (AK 79). Let us then start from a reconstruction of this central notion of a statement. Such reconstruction is by no means an easy task. The 60odd pages of The Archeology of Knowledge that elaborate on this concept are not only the most difficult part of the whole book, but they also contain some of the least transparent passages of Foucault's whole oeuvre. It is thus hardly surprising that even as distinguished Foucault scholars as Deleuze, Dreyfus and Rabinow either confine themselves to repeating, by and large, the wording of the central passages (Deleuze 1988: 1--22), or settle for exploiting Foucault's misunderstanding of the speech act theory to quickly equate statements with speech acts (Dreyfus and Rabinow 1982:46).

The simple - yet crucial - step of my interpretation is to take seriously Foucault's suggestion that dealing with statements means "dealing with an enunciative function" that relates signs "to a field of objects ... a number of possible subjective positions ... a domain of coordination and coexistence [and] ... a space in which they are used and repeated." (AK 106) The natural way of rendering this passage intelligible is, obviously, to take the notion of a function at its mathematical face value. Whether a string of signs is a statement or not, Foucault tells us, depends on its relation to other factors. What then is more inviting than to express this dependence with a function in its most general, set-theoretical sense? After all, functions in this sense are precisely the kind of things by means of which dependencies can be formally expressed. My proposal then is that a Foucauldian 
statement is an ordered quintuple

$$
<r_{i}, p_{i}, a_{i}, l_{i}, s_{i}>
$$

and that the set of possible statements (É) can be represented by a function $\left(f_{\dot{E}}\right)$ as follows:

$$
f_{\dot{E}}: R \times P \times A \times L \rightarrow S
$$

Here $R$ is the class of "referentials", $P$ is the class of "subjective positions", $A$ is the class of "associated domains", $L$ is the class of spatiotemporal locations, and $S$ is the class of strings of signs. All of these five coordinates, or ingredients, of a statement call, of course, for some explanation.

(1) To begin with the notion of referential, Foucault informs us that in order to qualify as a statement, a string of signs must "refer to something", i.e., must refer to objects and states of affairs. Each statement has as its "correlate ... a group of domains [of objects and states of affairs, e.g.] a domain of material objects, ... a domain of fictitious objects ... a domain of spatial and geographical locations" (AK 91). This condition for statementhood is of course tantamount to the central idea of intensional semantics. In the latter, a proposition specifies a set of possible worlds in which it is true, viz., in intensional semantics a proposition specifies a set of possible worlds that contain states of affairs and objects to which the proposition refers. Similarly, a Foucauldian statement is related to a set of domains of states of affairs and objects: statements are correlated with domains in which they have reference.

There is, however, one additional complication in Foucault's notion of referential that is not captured by this parallel. Foucault draws a distinction between correlate and referential to the effect that whereas the correlate consists of the domains of objects, the referential consists of "laws of possibility" or "rules of existence" of these various domains (AK 91). Thus different domains are not pregiven. Instead, they themselves depend upon various factors and operations. (What kinds of domains of objects are possible or accessible, e.g., for a science at a given time, depends on social as well as science-internal factors and operations, like social institutions, acts of delimination, and grids of classification. (AK 412)) This differentiation between correlate and referential can be captured by treating $R$ not as a class of domains of objects and states of affairs, but rather as a class of characteristic functions that map the Cartesian product of domains $(D)$ of objects and states of affairs, on the one hand, and the mentioned factors $(F)$ and operations $(O)$, on the other hand, into the two values 'possible' $(M)$ and 'impossible'
$(-M):$

$$
f_{R}: D \times F_{1} \times \ldots \times F_{n} \times O_{1} \times \ldots \times O_{n} \rightarrow\{M,-M\}
$$

(2) To turn to the class of subjective positions, $P$, Foucault writes that it is constitutive of a statement to prescribe "a particular, vacant place that in fact may be filled by different individuals ... To describe a formulation qua statement does not consist in analyzing the relations between the author and what he says ... but in determining what position can and must be occupied by any individual if he is to be the subject of it." (AK 96) For example, under normal conditions, the statement " $2+2=4$ " prescribes for its utterer a neutral, timeless, detached position, whereas the statement "I love Ronny" prescribes a position of emotional involvement or irony.

It seems natural to suggest that Foucault's subjective position parallels some ingredients in the speech act theory of Austin and Searle, i.e., foremost the idea that the successful performance of different speech acts is contingent upon specific beliefs, attitudes, and self-presentations of the speaker or writer. $^{2}$

(3) Each statement is always related to a domain of other statements that figure as its "associated domain" (AK 96), "collatoral space", "background of a whole verbal network", "associated field" (AK 98), "enunciated field", or "enunciative network" (AK 99). No statement can ever appear in isolation. Unfortunately, Foucault does not tell us very much about how to specify the upper limits this field. Perhaps this associated domain is little else but a "discursive formation", that is, a large historical group of statements like, e.g., general grammar or natural history in the 18th century. (We shall return to this notion below.) Although Foucault does not specify the upper limits of the associated field, he nevertheless makes it clear that the associated domain of a statement is much more than just an immediate context or co-text. (AK 97) In fact, what counts as a possible context of some statement is determined by the rules and the structure of its associated domain. Thus, for instance, restrictions on context work differently in poetry and mathematics: whereas the two statements "I love Ronny" and " $2+2=4$ " can immediately follow each other in a poetic text, they can hardly do so in a mathematical treatise.

(4) As regards the class of locations, $L$, especially Foucault's distinction between "statement", "enunciation", and "formulation" becomes important. Both formulation and enunciation are bound to a single spatiotemporal location, but whereas a formulation is the act of stating a statement, an 
enunciation is merely the act of uttering a string of signs. (AK 98, 101) Now, because an enunciation is merely an utterance of signs - and not yet an utterance of a statement-it allows for an abstraction over its spatio-temporal constants: "... this uniqueness [of the enunciation] allows for a number of constants - grammatical, semantical, logical by which one can, by neutralizing the moment of enunciation and the coordinates that individualize it, recognize the general form of a sentence, a meaning, a proposition." (AK 101)

The statement level, however, cannot be thus abstracted. Insofar as an enunciation is an enunciation of a statement, i.e., insofar as an enunciation is - or is treated as - a formulation, the application of the type-token distinction is ruled out. Foucault postulates that a statement must have "material existence ... a substance, a support, a place, and a date" (AK 100-1). This condition does not collapse the distinction between formulation and statement, since Foucault regards the statement as repeatable despite its "materiality" or spatiotemporal boundedness. He characterizes the statement as "repeatable materiality" (AK 102, 105), a characterization that Foucault admits to be "paradoxical" (AK 105).

Speaking of a repeatable materiality does indeed smack of paradox. What forces Foucault to bite the bullet and accept this paradox is likely to be the dilemma of having to choose between a HusserlianPlatonistic conception of ideal, repeatable meaning entities, on the one hand, and the unrepeatability of dated statements, on the other hand.

(5) To turn, finally, to the sign coodinate of the statement, it suffices to mention that Foucault is here not merely thinking of linguistic signs, but also of graphical representations. (AK 86)

\section{Statements and discursive formations}

The Archeology of Knowledge informs us that discourses are "group[s] of sequences of signs, insofar as they are statements", that "the term discourse can be defined as the group of statements that belong to a single system of formation" (AK 107), that "we shall call a discourse a group of statements insofar as they belong to the same discursive formation" (AK 117), and that "discursive formations are, strictly speaking, groups of statements" (AK 115). These passages suggest that discursive formation is a broader concept than discourse, i.e., that a discursive formation consists of several discourses (that in turn consist of statements). Since Foucault is not very explicit about the relations between discourses and discursive formations, I shall subsequently concentrate on the relation between statements and discursive formations.

As the first part of The Archeology of Knowledge outlines, discursive formations are what Foucault's new history of science takes as its objects. To start with some examples, general grammar, natural history, and the analysis of wealth in the 18th century, are three different discursive formations. They are distinct from the discursive formations of philology, biology, and economics of the 19th century. Foucault emphasizes that discursive formations cannot be identified, and thus delimited from one another, by identifying for each of them a single central object, e.g., madness, by identifying for each a single common mode of language or "enunciative modality", e.g., descriptive or prescriptive language, by identifying for each a clearly confined small set of concepts, or by identifying for each a single theory or theme (AK 32-5). Instead, a discursive formation has been identified once a stable law of dependence or interrelation can be detected, a law that expresses the dependencies and interrelations between conditions of the possibility for a variety of objects, a variety of enunciative modalities, a variety of concepts, and a variety of theories or themes. (AK 32-5) That is to say, a discursive formation always allows for plurality vis-à-vis objects, modalities, concepts and theories; what constitutes its unity and identity is rather that this plurality emerges on the basis of a single set of rules.

Formally, a discursive formation (df) can thus be characterized by a function $\left(f_{d f}\right)$ that maps sets of objects $(O)$, sets of enunciative modalities (EM), sets of concepts $(C)$, and sets of theories $(T)$ into the values 'possible' and 'impossible':

$$
f_{d f:}: O \times E M \times C \times T \rightarrow\{M,-M\}
$$

Foucault suggests that these four elements of a discursive formation (objects, enunciative modalities, concepts, theories) correspond to the $r-, p-, a-$, and 1 -coordinates of the statement (AK 116). Indeed, the referential corresponds to the rules of object formation, and the subjective position can roughly be related to enunciative modalities. The associated domain can be treated as the counterpart of the concepts element, since The Archeology of Knowledge proposes that concepts and their interrelations can be studied only within sets of statements, their different forms of succession, coexistence, and translation. (AK 56-7) It is less clear, however, how the location of a statement 
can find an equivalent within the constituents of a discursive formation, and how the formation of theories is paralleled in the coordinates of the statement.

Be this as it may, note that even though discursive formations are made up of statements, not every statement can be part of just any discursive formation. Rather, each discursive formation is characterized by a specific "law of coexistence"(AK 116), "principle of rarification" (AK 119), or "law of enunciative poverty" (AK 120) that restricts the discursive formation to precisely the statements it in fact has. This suggests that it is an essential attribute of a discursive formation to contain exactly the statements it is found to contain.

When couched in this way, it is inviting to suggest that what appears as "enunciative poverty" might just as well be regarded as "enunciative plenitude". Remember that Leibniz treats a possible world as a plenum because everything that is possible, on the basis of the laws of the world in question, must be actual sooner or later. Analogously, we might say that a discursive formation is also characterized by plenitude: every statement that is possible, according to the laws of the discursive formation in question, must be actual sooner or later within this discursive formation. To appreciate this point, note only that it is the task of archeology to describe the rules of emergence of statements within a discursive formation. It follows that whenever we are still left with possible but non-actual statements for a given discursive formation, we have as clear an indication as any that we have not yet identified all of the relevant rules. Indeed, Foucault tells us that "[t]here is no such thing as a latent statement..." (AK 109). Furthermore, when speaking about unactualized possible statements, he refers to this possibility as one with respect to language as langue, not with respect to the "law of poverty" of a discursive formation: "We must look therefore for the principle of rarification or at least non-filling of the field of possible formulations as it is opened up by the language (langue)." (AK 119)

Foucault's claim that each discursive formation is characterized by its "law of coexistence" may be reconstructed by saying that the set of languepossible statements, $\boldsymbol{E}$, is divided by a reflexive and symmetric binary relation of discursive compatibility. This relation orders the elements of $E$ into subsets

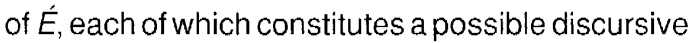
formation. The usefulness of this reconstruction lies in the possibility of relating Foucault's theory of discursive formations to possible worlds theories; after all, within the latter conception, possible states of affairs, objects, monads, or individuals are conceived of as being distributed into different possible worlds by the relation of compossibility. The parallel also holds insofar as Foucault's theory as well as possible worlds theories, claim that there cannot be statements or individuals outside of discursive formations or possible worlds. Foucault's commitment to this idea is obvious from his insistence that it is constitutive for a statement to be related to an associated field of other statements.

The suggested parallel between Foucault and possible worlds theories can even be extended further. A close examination of Foucault's ideas on the relation between statements and discursive formations reveals that his theory of discursive formations even has a specific counterpart within the broad spectrum of possible worlds theories. This counterpart is found in the theories of Leibniz and David Lewis. For instance, just as Leibniz and Lewis deny transworld identity, i.e., just as Leibniz and Lewis deny that an object can be in more than one world, Foucault denies that a statement can appear in more than one discursive formation.

Leibniz rejects transworld identity on account of his conviction that all attributes are essential: for Leibniz it makes no sense to ask "what would have happened if Peter had not denied Christ" since this question amounts to asking "what would have happened if Peter had not been Peter, for denying is contained in the complete notion of Peter". Note also that Leibniz thought that in picking out one complete concept, say of Adam, we in fact pick out a world: since Adam mirrors all other concepts within his world, if anything - even thousands of years later - were different from what it is or has been, Adam would not have been Adam. (Mates 1986: 140-1) An additional reason that pushed Leibniz towards denying transworld identity is the idea that individuation and identity make sense only within one and the same world, i.e., within one and the same space-time framework. (Rescher 1981: 84-100)

Foucault's account of the 'statement / discursive formation' relation 'mirrors' Leibniz's conception in several ways. First of all, Foucault proposes that the statement is determined in its identity by "conditions and limits ... that are imposed by all other statements among which it figures" and that identity of wording is not enough to safeguard identity on the statement level. Thus, for example, the statement that the earth is round, is a different statement in the discursive formations before and after Copernicus. (AK 103) In other words, a statement is repeatable only within one and the same discursive formation. 'Transdiscursive identity' is ruled out.

Analogously to Leibniz's idea of mirroring, 
Foucault is also committed to the idea that every statement ultimately reflects the discursive formation of which it is a part. As The Archeology of Knowledge informs us, the following list of items determines the identity of a given statement: "the series of other formulations within which the statement appears and forms one element ... all the formulations to which the statement refers (implicitly or not), either by repeating them, modifying them, or adapting them, or by opposing them, or by commenting on them ... all the formulations whose subsequent possibility is determined by the statement ... all the formulations whose status the statement in question shares, among which it takes its place ... with which it will fade away, or with which, on the contrary, it will be ... offered, as a possible object, to future discourse

..." (AK 98-9) Here it is hard to avoid the impression that in collecting the items of this list, one in fact enumerates all of the statements of a given discursive formation.

Note, furthermore, that the Leibnizian idea of space and time as specific orders of things within a given world, also sounds like an idea familiar from Foucault's writings. After all, the metaphor of space makes a frequent appearance in Foucault's archeological writings, and it is natural to speak of a discursive formation as a space of statements. (Deleuze 1988: 4-6) The same parallel also holds with respect to time since Foucault questions the application of a transdiscursive time or "calendar": "By deploying discourse throughout a calendar, and by giving a date to each of its elements, one does not obtain a definitive hierarchy of precessions and originalities; this hierarchy is never more than relative to the systems of discourse that it sets out to evaluate." (AK 143)

While Foucault clearly rejects the notion of transdiscursive identity, he does, nevertheless, allow for transdiscursive similarity. This is yet another feature of his conception that has a parallel in Leibniz and Lewis. ${ }^{3}$ Due to the writings of Lewis, the idea of transworld similarity has gained currency under the label of "the counterpart theory" (Lewis 1968). The basic line of this theory is that even though all individuals are worldbound, counterfactual statements, and thus the distinction between essential and inessential attributes, are still possible. Although I can only be a member of one world, say $w_{1}$, I can still have "counterparts" in other worlds, where a counterpart of mine is a member of some other world, say $w_{2}$, being more like me than any other member of $w_{2}$. In Lewis' opinion, this conception allows us to uphold the distinction between essential and inessential attributes while sticking to the worldboundness of individuals all the same: my essential attributes are those attributes that I share with all of my counterparts, whereas my inessential attributes are those that I do not thus share. (Lewis 1968: 122)

Now, in Foucault's case we are certainly not dealing with essential or inessential attributes of statements. Yet what we do find - or what is more than natural to attribute to Foucault - is the idea that a statement can have counterparts in other discursive formations. Thus, when dealing with the comparison between different discursive formations, Foucault suggests that we can identify "archeological isotopia": "entirely different concepts (like those of value and specific character [in the discursive formations of 17 th century economics and of natural history respectively] ...) occupy a similar position in the ramification of their system of positivity [i.e., discursive formation] - although their domain of application, their degree of formalization, and above all, their historical genesis makes them quite alien to one another." (AK 161) It is true that Foucault is talking here about concept counterpart, not statement counterparts. However, the transition from the first to the second can be justified by Foucault's pronouncement that concepts function only within statements.

Furthermore, in another passage, Foucault argues that even though a statement cannot appear in two different discursive formations, it can still be related to statements within another discursive formation that are either "linguistically analogous", i.e., that have the same syntactic-lexical surface structure, or that are "logically identical", i.e., that are equivalent. (AK 145) If we are to take these two lastmentioned criteria as two further criteria of statement similarity across discursive borders, then Foucault certainly owes us a theory as to how these different criteria are to be hierarchized. Unfortunately, such a theory is not provided in The Archeology of Knowledge.

We can push the parallel between Foucault's theory of discursive formations and possible worlds theories one more step further by attending to Foucault's interest in the similarity of discursive formations as a whole. In Lewis' possible worlds conception every possible world is surrounded by a sphere of overall similar worlds. This notion of similarity of worlds is needed to account for the semantics of counterfactual sentences. For instance, to say that 'If Foucault were an American, Foucault and Ronald Reagan would be compatriots' is to say that there is a set (sphere of accessibility) of possible worlds, such that they all are overall similar to our world and such that Foucault - or his counterparts figure as American citizens. (Lewis 1973: 8-9) 
Foucault, in turn, is interested in the question under what conditions two or more discursive formations form a "region of interpositivity" or an "interdiscursive group" (AK 159). This question subsequently leads up to the problem under what conditions two or more discursive formations are accessible to one another. In other words, Foucault holds that communication between discursive formations is possible only when the discursive formations in question are similar.

Contrary to Lewis, in whose Counterfactuals (1973) the notion of similarity between possible worlds remains a primitive, unspecified concept, Foucault provides us with three criteria for similarity between discursive formations. Above, we have already referred to the first one, to wit, the existence of "archeological isotopia", i.e., concepts or statements with a similar function. The second and third criteria are "archeological isomorphisms" and "archeological models". Two discursive formations are archeologically isomorphic if and only if the emergence of their respective statements are governed by "similar rules". Two discursive formations share the same "archeological model" if and only if, in addition, these similar rules are ordered in the same way. (AK 160-1) (Note that Foucault's insertion of "similar" suggests that he does not wish to allow for transdiscursive identity even with respect to rules.)

Now, since similarity between discursive formations is the condition of the possibility of their "law of communication", i.e., their accessibility to one another, it is inviting to ask what kind of accessibility relation Foucault's similarity criteria specify, and to what system of modal logic this accessibility relation corresponds. After all, different systems of modal logic, like $S 4, S 5, T$, and $B$, are semantically distinguished precisely by whether the accessibility relation between possible worlds is reflexive, and/or symmetric, and/or transitive. (Hughes and Cresswell 1968: 62-81)

First, the accessibility relation between discursive formations must certainly be reflexive since every discursive formation must be similar to itself, and thus acessible to itself. Yet the accessibility relation is neither symmetric nor transitive. Thus it turns out to correspond to the accessibility relation that characterizes system $T$ of modal logic. To see why it cannot be transitive, note that a discursive formation, $d f_{f}$, can be similar to another discursive formation, $d f_{2}$, with respect to one set of rules, $R_{1}$, and similar to another discursive formation, $d f_{3}$, with respect to another set of rules, $R_{2}$, without that $d f_{2}$ and $d f_{3}$ share any common, or similar, rules. Foucault himself mentions that a discursive formation can "enter simultaneously into several fields of relations", viz., several "regions of interpositivity" (AK 159). Clearly, for these "several fields" to remain distinct, for them not to collapse into one larger region of interpositivity, it must be possible for a discursive formation to be accessible from, and have access to, at least two other discursive formations that are not accessible to one another. Finally, the question whether the accessibility relation is symmetric, must also be answered negatively. This is important since it suggests that similarity between discursive formations is only a necessary but not a sufficient condition for accessibility. Certainly, similarity is a symmetric relation: if $A$ is similar to $B$, then $B$ is also similar to $A$. Yet when one discursive formation is subordinated to another (AK 161), it seems natural to allow for the possibility that the communication channel is used only in one direction. In such a case then, the accessibility relation is not symmetric, however similar the two discursive formations happen to be.

Before leaving the problem of communication between different discursive formations, one rather obvious critical question has to be adressed: the apparent contradiction between Foucault's allowing for interdiscursive communication, on the one hand, and his rejection of transdiscursive statement identity, on the other hand. How can one discursive formation influence another, if no statements can cross their border? - Two answers can be suggested in answer to this question. On the one hand, one might suggest that influence in this case does not have to involve any exchange of statements. The influence of one discursive formation, say $d f_{1}$, on another, say $d f_{2}$, might simply consist in the fact that $d f_{2}$ adopts similar objects, or modes of enunciations. On the other hand, recall that Foucault allows for "linguistic analogy" between statements of different discursive formations, i.e., identity "from the point of view of grammar (vocabulary, syntax, and the language (langue) in general)". He also speaks of this linguistic analogy as "translatability" (AK 145). Perhaps we are then to say that even though a statement (é $\varepsilon d f$ ) cannot be transferred to another discursive formation, it can at least be translated into a statement of another discursive formation ( $e_{j} \varepsilon d f$ ), where the second statement ( $\dot{e})$ may then be regarded as a counterpart of the first $\left(\hat{e}_{j}\right)$.

\section{Change and rupture - Tom and Larry}

Next, let us turn to the problem of change within a discursive formation, and the issue of the 
replacement of one discursive formation by another. With this latter question we reach Foucault's notion of rupture, not only a notion that has been related to Thomas Kuhn's philosophy of science, but also a notion that - at least in some quarters - has given Foucault's archeology a bad name.

We have already had occasion to see that the development of a discursive formation can be compared to the course of events within a Leibnizian possible world: everything that is possible according to the laws of a discursive formation must eventually become actual. A discursive formation unfolds according to its internal rules of development just like a Leibnizian world develops according to its internal laws. It is the task of archeological analysis to determine these rules, laws, or principles. These rules determine how statements emerge, circulate, are repeated, transformed, preserved, or forgotten, and how, correlatively, objects of discourse, enunciative modalities, concepts, and theories emerge, circulate, are repeated, transformed, preserved, or forgotten. The central motor of these processes, are various contradictions between statements or theories, e.g., small-scale contradictions within a discursive formation, deep-rooted contradictions within a discursive formation, i.e., contradictions that lead to the emergence of subdiscourses, or "extrinsic" contradictions between concepts, statements, and theories of different discursive formations. (AK 154)

The rules that determine the identity of a discursive formation are not all on one level, however. On the one hand, there are laws that restrict the emergence, circulation, and transformation of statements during the whole period of time during which a given discursive formation exists, laws that govern the discursive formation throughout its (sub-)discourses. On the other hand, there are laws, principles or rules that are less general and less comprehensive. The latter do not apply during the whole 'lifespan' of a discursive formation; just like the statements they determine, these rules too can be transformed and even disappear. (AK 147)

Foucault suggests that these two different sets of rules are reflected - although not expressed and formulated - in statements of different discursive status. He thus speaks of "governing statements" that put "rules into operation in their most general and most widely applicable form; using them as a starting-point, one can see how other objects, other concepts, other enunciative modalities, or other strategic [theory] choices may be formed on the basis of rules that are less general and whose domain of application is more specific." (AK 147) It is this distinction between general and fundamental rules, on the one hand, and more specific, and less comprehensive, rules, on the other hand, that is of crucial significance for Foucault's analysis of the replacement of one discursive formation by another.

As already indicated, it is here that Foucault makes use of the notions of "rupture", "break", and "discontinuity". The Archeology of Knowledge accuses traditional history of thought of having overemphasized continuity in history (AK 169), and Foucault accordingly calls for the study of "discontinuity (threshold, rupture, mutation, transformation)" (AK 5). The role of discontinuity in archeological history is threefold. First, discontinuity is used as a "systematic hypothesis" by the historian, second, "it is the result of his description (and not something that must be eliminated by means of his analysis)", and third, "it is the concept that the historian's work never ceases to specify" (AK 8-9).

But what is the nature of a discontinuity, a rupture orbreak in the history of thought? Are we to conceive of a Foucauldian rupture as a Kuhnian "irreversible Gestalt-shift", or "conversion experience", as an instantaneous break that renders discursive formations incommensurable, as a barrier that makes researchers working in historically subsequent discursive formations live in different worlds? (Kuhn 1962) Some of Foucault's statements indeed suggest this kind of interpretation. For instance, The Order of Things (1966/1974: xii) speaks of "the suddenness and thoroughness with which sciences were sometimes reorganized", and the same book tells us that after the "great discontinuity" ( $x$ xii) at the beginning of the nineteenth century, "Classical thought ceased ... to be directly accessible to us" (304).

These kinds of pronouncements are probably responsible for the widespread conception of deep and thoroughgoing parallels between Foucault's archeology and Kuhn's philosophy of science. Interestingly enough, this view has, at least in part, made Foucault a respectable figure in Anglosaxon analytical philosophy, a brand of thought that otherwise is characterized by a certain neglect not to say contempt - for recent French philosophy. Thus, e.g., Larry Laudan, in his recent book Science and Values (1984) refers to Foucault repeatedly as a historian of science who, like Kuhn, conceives of scientific change as "simultaneous rather than sequential" (1984: 69). ${ }^{4}$

However, this allegedly Kuhn-Foucauldian position does not find Laudan's sympathies. Indeed, he goes on to present an alternative model of scientific change, an alternative model that he regards as a refutation of the Kuhnian, and ipso facto Foucauldian, conception. In the following, I 
shall argue that counter to what Laudan assumes, Foucault's theory of rupture is not Kuhnian. We shall see that it is in fact an anticipation of Laudan's own view.

Relying on Kuhn's The Structure of Scientific Revolutions, Laudan regards a paradigm as constituted by an ontology, i.e., a conceptual framework for classifying objects, a methodology, and cognitive goals and ideals, e.g., goals like simplicity, and scope of explanationary power. According to Laudan, Kuhn holds that the change from one paradigm to another is more fundamental than just the trading in of one ontology for another, or of one methodology for another, or of one set of cognitive goals for another. Rather, the shift from one paradigm to another is a simultaneous, wholesale change with respect to all three ingredients of a paradigm. In other words, ontology, methodology, and axiology come in one "inseparable package" (Laudan 1984: 71). This thesis makes paradigm changes turn out to be "abrupt and global ruptures" (70).

Laudan's arguments against Kuhn are directed precisely against this inseparable package view. Drawing on examples from the history of physics and chemistry - examples earlier interpreted by Kuhn as constituting paradigm shifts - Laudan shows (76-7) that the changes involved are not instantaneous ones from

$$
\begin{aligned}
& \left(\text { time }_{1}:\right) \text { ontology } \\
& \text { to } \\
& \text { (time } e_{2}: \text { methodologtology } y_{1}-\text { axiolog } y_{1}
\end{aligned}
$$

but rather step-by-step revisions of the three constituents, e.g.,

(time : $_{1}$ ) ontology $y_{1}$ - methodology $y_{1}$ - axiology (time ${ }_{2}$ :) ontology $y_{2}$ - methodology $y_{1}$ - axiology (time : $_{3}$ ) ontology $y_{2}$ - methodology $y_{2}$ - axiology, $\left(\right.$ time $_{4}$ :) ontology $y_{2}$ - methodology $y_{2}$ - axiology

Laudan suggests that only a superficial historian - Laudan baptizes him "Tom" (ibid. 78) — can see abrupt change where in fact the change is almost always gradual. Tom will be so struck by the shift from time ${ }_{1}$ to time ${ }_{4}$, perhaps happening in just one decade, that he will be blind to see the intermediate stages: "If Tom decides to call the view that scientists eventually come to hold 'Paradigm 2', and the view from which they began 'Paradigm 1', then he will be able to document the existence of a massive paradigm shift between what (at our remoteness in time) appear to be conceptually distant and virtually incommensurable paradigms." (ibid.)
With this rough outline of Laudan's theory, we can turn to the question whether Tom would feel comfortable in the company of Michel. As I have already indicated above, my answer to this question is negative. The answer must be negative not only because of Foucault's explicitly stated theory of rupture in The Archeology of Knowledge, but it must also be negative in the light of his historicalarcheological investigations, i.e., Madness and Civilization (1961/1971), The Birth of the Clinic (1963/1976), and The Order of Things (1966/1974).

In the Archeology, we read that a rupture "is not an undifferentiated interval - even a momentary one - between two manifest phases; it is not a kind of lapsus without duration that separates two periods". Rather, a rupture between two successive discursive formations is "always a discontinuity specified by a number of distinct transformations" (AK 175), and that "rupture is the name given to transformations that bear on the general rules of one or several discursive formations" (AK 177). These transformations concern rules, laws and principles governing the four elements of a discursive formation: objects, enunciative modalities, concepts, and theories. They also concern the interrelations between these rules, and the interrelations between different discursive formations. (AK 173)

A Foucauldian rupture is thus a transformation within the most general rules of a discursive formation, a transformation that - contrary to what Laudan alleges - is not instantaneous. Further evidence to the effect that the four central ingredients of a discursive formation do not change wholesale, that is to say, that they do not form one "inseparable package", is easily forthcoming. It is true that Foucault claims that "the appearance of a discursive formation is often correlative with a vast renewal of objects, forms of enunciation, concepts, and strategies" (AK 171), but not only does he hasten to add a counterexample ("General Grammar was established in the seventeenth century without much apparent alteration in grammatical tradition", ibid.), he also writes that the replacement of one discursive formation by another does not entail "that all objects or concepts, all enunciations or all theoretical choices [of the earlier discursive formation] disappear" (AK 173). This suggests that the change involved in a rupture is - although happening within a short period of time - gradual rather than instantaneous.

This suggestion is also supported by Foucault's historical inquiries. What Madness and Civilization studies is not the immediate, break-like emergence of our modern conception of madness, but rather the gradual, step-by-step emergence of this conception from the Renaissance to the 19th 
century. In The Birth of the Clinic, Foucault studies the rupture in medical thought roughly between 1780 and 1825 . Again the change under scrutiny is gradual, not immediate: the period under investigation is devided into four phases and the transformations taking place from one phase to the next are everything but revolutionary. It is only when taken together that these phases illuminate the radical, rupture-like change in medical thinking between the outer limits of the whole period. Finally, The Order of Things, even though it speaks of "two great discontinuities in the episteme of Western culture: the first inaugurates the Classical age (roughly half way through the seventeenth century) and the second, at the beginning of the nineteenth century" (1966/1974: xxii), does suggest that the emergence of modern thought - the second rupture — is "possible to follow step by step" (ibid. 217). Unfortunately, however, in his best known work, Foucault does not go as far in this analysis as he does in his two earlier books. Yet even here it must be obvious even to a superficial reader that the change from the classical to the modern period is not understood as instantaneous and package-like. After all, the transformation is dated roughly between 1775 and 1825 and a phase of gradual transition is explicitly allowed for. In this phase, the pillars of Classical thought are replaced gradually. (1966/ 1974: 221)

In the light of this evidence, it is certainly justified to stress the discontinuity between Foucault's and Tom's - or Kuhn's - conceptions. As much as Leibniz opposes the idea of jumps in nature ("... our understanding will not put up with gaps ..." (1699: 157)), as clearly does Foucault reject the notion of gaps in the history of epistemes. Foucault's repeated emphasis on ruptures is best understood not as an interest in the unexplainable but rather as an insistance on the idea that not all changes are on a par. A one-sided search for continuity rather than discontinuity easily leads one to treat all changes of discursive formations as discourse-internal, i.e., as happening within one and the same discursive formation. Thus more fundamental changes in the history of thought are assimilated to more superficial ones.

Finally, it must also be mentioned that Foucault nowhere claims that researchers of successive discursive formations are - in principle - unable to understand one another. What Foucault does claim, however, is that those discursive formations that are separated from us by a rupture are not "directly [!] accessible to us" (1966/1974: 304). This statement must, in the light of Foucault's Archeology as well as in the light of his historical studies, be read as a warning against anachronistic assimilations of earlier scientific concerns to our own, rather than as a plea for incommensurability. In fact, to attribute the incommensurability thesis to Foucault would mean to render his whole enterprise unintelligible since, after all, archeology itself must have access to earlier discursive formations.

\section{Critical conclusion}

In this concluding section I shall summarize the results of my reconstruction of Foucault's archeology, and point out at least some of the difficulties, problems, and questions that beset archeology.

(1) Foucault's notion of a statement is less unclear than one might conclude from a superficial reading of Part II of The Archeology of Knowledge. A statement is the result of the working of an "enunciative function" that maps the Cartesian product of referentials, subjective positions, associated fields, and locations into strings of signs. Several questions remain, however. For instance, we already had occasion to lament that the coordinates of the statement and the ingredients of a discursive formation do not match. Another problem is that no good argument is given as to why we should restrict the coordinates of a statement in the suggested way. The question why we should not add, e.g., an addressee or a media coordinate, is left unanswered. One also wonders whether Foucault has indeed laid bare a level of language that has remained hidden up until the publication of The Archeology of Knowledge. The parallels between his conception of énoncés and intensional semantics certainly suggests otherwise.

(2) The main results of the comparison between discursive formations and possible worlds can be summarized by means of the following chart: 


\section{Possible worlds theories}

(I) possible objects/individuals are distributed into different possible worlds by the relation of compossibility (Leibniz)

(II) the possible world as plenum (Leibniz)

(III) possible worlds and monads develop according to their internal laws (Leibniz)

(IV) all objects/monads of a given world are essential to it (Leibniz)

(V) no object outside of possible worlds (Leibniz)

(VI) no transworld identity (Leibniz, Lewis)

(VII) space and time are world-specific orders of individuals/objects (Leibniz)

(VIII) objects/individuals can have counterparts in other possible worlds (Leibniz, Lewis)

(IX) similarity between possible worlds, possible worlds come in spheres (Lewis)

(X) accessibility relations between possible worlds (modal logic)

This parallelism between Foucault's theory of discursive formations and the Leibniz-Lewisian conception of possible worlds naturally leads to a number of suggestions and questions.

First of all, note that the possibility of reconstructing Foucault's archeology by means of the possible worlds idiom brings Foucault in close contact with recent analytical philosophy. This fact alone is noteworthy since it provides at least a partial argument against those quarters of the philosophical scene that still believe in something of an incommensurability between the continental and the analytical philosophical discourses.

Second, the possibility of a mathematization of Foucault's theory of discursive formations, a possibility that the parallel with the possible worlds theories opens up, hardly contradicts Foucault's own intentions. The "threshold of formalization" is defined in The Archeology of Knowledge as the final threshold that a given system of knowledge has to cross, after having earlier established norms of coherence and verification ("threshold of epistemologization") and after having earlier adopted formal criteria or laws for the construction of propositions ("threshold of scientificity") (AK 187). Furthermore, in The Order of Things we read that even in the human sciences, one may "make use of mathematics as a tool; some of their procedures

\section{Foucault's theory of discursive formations}

(I') possible statements are distributed into discursive formations by the relation of discursive compatibility

(II') the discursive formation as plenum(and poverty)

(III') discursive formations develop according to their internal laws

(IV') all statements of a given discursive formation are essential to it

(V') no statement outside of discursive formations

(Vl') no transdiscursive identity

(VII') space and time are orders of statements, orders that are different for different discursive formations

(VIII') statements can have counterparts in other discursive formations

(IX') similarity between discursive formations, regions of interpositivity

$\left(X^{\prime}\right)$ accessibility relations between discursive formations

and a certain number of their results can be formalized. It is undoubtedly of the greatest importance to know those tools, to be able to practice those formalizations ..." (1966/1974: 349)

Third, as important as is Foucault's affinity with modern analytical philosophy, as interesting is his affinity with the thought of Leibniz. After all, it is first and foremost Leibniz' conception of possible worlds that resembles Foucault's theory of discursive formations. The question that naturally arises here is whether the parallel between Foucault and Leibniz can be extended even further than this paper suggests, i.e., whether Leibnizian ideas can be detected in Foucault's historical studies, and whether the affinities with Leibniz can still be identified in Foucault's writings of the 70's and 80's. An answer to this question obviously lies beyond the scope of this paper. Therefore, I shall confine myself to two other observations.

First, note how natural it seems to speak of Foucault's Leibnizian treatment of historical discourses as a "monadologization of history". When couched in this way, a further parallel immediately suggests itself, to wit, the parallel with the thought of Walter Benjamin. Benjamin writes that "[f]or a part of the past to be inflicted by the present, no continuity may hold between them" (1983: 587), that "[i]t is demanded by the monadological structure 
of the object of history that it is torn out of the historical continuity", or that "[t]he destructive or critical moment of the materialistic writing of history shows effect in its tearing apart of historical continuity; in this tearing apart the historical object constitutes itself for the first time." (1983: 594) Foucault scholarship has not yet tackled this highly promising affinity that perhaps has more to offer than the prevailing comparisons between Foucault and the Frankfurt school. ${ }^{5}$

Second, it is astonishing to realize that the triad 'Descartes - Spinoza - Leibniz' seems to have something of a counterpart in French philosophy after World War II. Recall that Sartre and MerleauPonty, among others, take their starting point from Husserl and that Husserl's most influential work in France was his Cartesian Meditations (Husserl 1931/1960). Furthermore, Foucault's one-time teacher, Althusser, at one point sought to develop his structural marxism by infusing it with the Spinozistic conception of causality. Althusser even wrote that "if we have not been structuralists, we today can admit why not: ... we were Spinozists" (1975: 70). To place Foucault in this triad is inviting not only because of his Leibnizian theory of discursive formations, but it is also natural because of the parallels that exist between Foucault's criticism of the phenomenologists, on the one hand, and Leibniz' criticism of the Cartesians, on the other hand. For instance, where Leibniz stresses against Descartes that there can be no thought without the use of a pregiven sign system (1951: 8), Foucault stresses against Sartre and the phenomenologists that there can be no thought and no speech or writing without an anterior discursive formation and its rules of statement formation. (AK 122)

Turning from suggestions for further research to a critical remarks, the obvious question to be asked here is to what extent historical discourses are analogous to Leibnizian possible worlds. After all, possible worlds are spatiotemporally distinct and there thus cannot be any exchanges or causal links betweenany of them. Certainly, this looks like a highly problematic model for discursive formations. After all, historical discourses influence one another - a possibility that Foucault himself allows for and they presuppose or involve the activity of scientists that might participate in the production of more than one of them. Furthermore, different fields of science do not have sharp borders; if we are to conceive of them as sets of statements at all, then we must take these sets to be fuzzy: even though they might have a hard core of statements that determine the identity of the set in question, this core is usually surrounded by groups of statements that ultimately shade over into another discipline. We only have to think here of the discourses of linguistics and sociology, for example, to see the force of this objection. Between the hard core of linguistics, say syntactical theories, and the hard core of sociology, say theories of social institutions, we find a broad spectrum of conceptions and ideas, like sociolinguistics, speech act theories, theories of communicative action, that might be counted as being parts of either linguistics or sociology.

(3) Even though - contrary to what Laudan alleges - a Foucauldian rupture is not instantaneous, note how well the notion of an instantaneous switch from one discursive formation to its successor would fit the Leibnizian model. Such an immediate shift would go well with the idea that each discursive formation is a closed whole with clear limits, i.e., the successor of a given discursive formation would always be an altogether different set of statements. Alas, even though an instantaneous switch would go with the notion of a discursive formation as a set of statements, the latter squares badly with Foucault's actual conception of rupture as gradual change. Take, e.g., the case of a radical rupture from ...

$$
\begin{aligned}
& \text { (time } e_{i} \text { ) } d f_{1} \text { : objects } 1 \text { - modalities }{ }_{1} \text { - concepts } \\
& \text { to } \\
& \text { — theories } \\
& \left(\text { time }_{\mathrm{k}} \text { :) } d f_{2}: \text { objects }_{2}-\text { modalities }_{2}-\text { concepts }_{2}\right. \\
& \text { - theories }
\end{aligned}
$$

Now, if we allow for gradual change, then between $d f_{1}$ and $d f_{2}$ we possibly have three intermediate stages, among them, e.g.

$$
\begin{aligned}
& d f_{1}: \text { objects }_{1}-\text { modalities }_{1}-\text { concepts }_{1}- \\
& \text { theories }_{2}
\end{aligned}
$$

The problem then arises as to how we are to account for these intermediate stages. In The Order of Things Foucault seems to opt for regarding them as part of $\mathrm{df}_{1}$. The transition from the Classical discursive formations to their modern successors is treated as a transformation within the Classical formations. (1966/1974: 217-36) However, this procedure is hardly appropriate from the standpoint of The Archeology of Knowledge, since the latter bookholds that a new discursive formation emerges even if only one or two elements of a discursive formation, e.g., objects or enunciative modalities, change. Judged on the basis of The Archeology of Knowledge, it is natural to suppose that the intermediate stages between $\mathrm{df}_{1}$ and $\mathrm{df}_{2}$ are meant by Foucault to constitute so many different and 
separate discursive formations. Even though the monadological framework is thus preserved, the suggested 'solution' is hardly convincing. It lacks plausibility, among other things, because it needs to postulate that for every singleone of the possibly (very) short-living intermediate discursive formations there exists a single and unique set of statements, none of which can appear in any other of the intermediate stages.

Perhaps this difficulty has its root in the two different characterizations of what a discursive formation is. On the one hand, it is defined as a group of statements, while on the other hand, it is characterized by a specific combination of objects, enunciative modalities, concepts, and themes. While the latter characterization allows one to conceptualize transformations, the former rather calls for abrupt changes. ${ }^{6}$

\section{NOTES}

1. See, among others, Arac (1988), Bernauer and Rașmussen (1988), Cousins and Hussain (1984), Couzens Hoy (1986), Deleuze (1988), Dreyfus and Rabinow (1982), Major-Poetzl (1983), Smart (1983), Smart (1985).

2. See, e.g., Searle and Vanderveken (1985).

3. For Leibniz' position, see foremost Adams (1985).

4. Laudan (1977:241) has earlier characterized Foucault's program in harsher terms: "Foucaultian structuralism must rank as one of the most obscurantișt hiștoriographical fashions of the twentieth century. It says something about the state of mind of many intellectual historians that they are prepared to pay obeisance to a work like Foucault's which they generally concede to be unintelligible."

5. Affinities between Foucault and Benjamin were first suggested to me by Heini-Eliisa Hakosalo.

6. Marja Alestalo, Dagfinn Follesdal and Ilkka Niiniluoto have commented on an earlier version of this study, and I have greatly benefited from their suggestions.

\section{LITERATURE}

Adams, $R$.

1985 "Predication, Truth, and Transworld Identity in Leibniz". Pp. $235-284$ in J. Bogen and J. E. McGuire, eds., How Things Are. Dordrecht: Reidel.

Althusser. L.

1975 Elemente der Selbstkritik. Berlin: VSA.

Arac, J., ed.

1988 After Foucault. New Brunswick: Rutgers University Press.

Benjamin, $W$.

1983 Das Passagen-Werk. Erster Band. Frankfurt am Main: Suhrkamp.
Bernauer, $J$ and D. Rasmussen, eds.

1988 The Final Foucault. Cambridge, Mass.: The MIT Press.

Couzens Hoy, D., ed

1986 Foucault. A Critical Reader. Oxford: Blackwell.

Deleuze, $G$

1988 Foucault. Translated and edited by S. Hand London: The Athlone Press. Originally published in French in 1986.

Dreyfus, $H$. and $P$. Rabinow

1982 Michel Foucault. Beyond Structuralism and Hermeneutics. Brighton: The Harvester Press

Foucault, $M$.

1961/1971 Madness and Civilization. A History of Insanity in the Age of Reason. Translated by R. Howard. London: Tavistock. Originally published in French in 1961.

1963/1976 The Birth of the Clinic. An Archeology of Medical Perception. Translated by A. M. Sheridan Smith. London: Tavistock. Originally published in French in 1963.

1966/1974 The Order of Things. An Archeology of the Human Sciences. London: Tavistock. Originally published in French in 1966.

1969/1974 The Archeology of Knowledge. Translated by A. M. Sheridan Smith. London: Tavistock. Originally published in French in 1969

Hughes, G. E. and M. J. Cresswell

1968 An Introduction to Modal Logic. London: Methuen.

Husserl, E.

1931/1960 Cartesian Meditations. Translated by Dorion Cairns, The Hague: Martinus Nijhoff. Originally published in 1931.

Kuhn, Th

1962 The Structure of Scientific Revolutions. Chicago: University Press.

Laudan, L.

1977 Progress and Its Problems. Towards a Theory of Scientific Growth. London: Routledge \& Kegan Paul.

1984 Science and Values. The Aims of Science and Their Role in Scientific Debate. Berkeley: University of California Press.

Leibniz, G. W. von

1951 Leibniz-Selections. Edited by Philip P. Wiener. New York: Charles Scribner's Sons.

Lewis, D.

1968 "Counterpart Theory and Quantified Modal Logic". Journal of Philosophy 65: 113-26.

1970 "General Semantics". Synthese 22: 18-67.

1973 Counterfactuals. Cambridge Mass.: Harvard University Press.

Major-Poetzl, $P$.

1983 Michel Foucault's Archeology of Western Culture. Brighton: Harvester Press.

Mates, B.

1986 The Philosophy of Leibniz. Metaphysics and Language. Oxford: University Press.

Rescher, N

1981 Leibniz's Metaphysics of Nature. Dordrecht: Reidel.

Searle, J. and D. Vanderveken

1985 Foundations of Illocutionary Logic, Cambridge: University Press. 
Smart, B.

1983 Foucault. Marxism and Critique. London: Routledge and Kegan Paul.

1985 Michel Foucault. London: Tavistock.

Martin Kusch

Department of History

University of Oulu

Kasarmintie 8

SF-90100 Oulu

Finland 